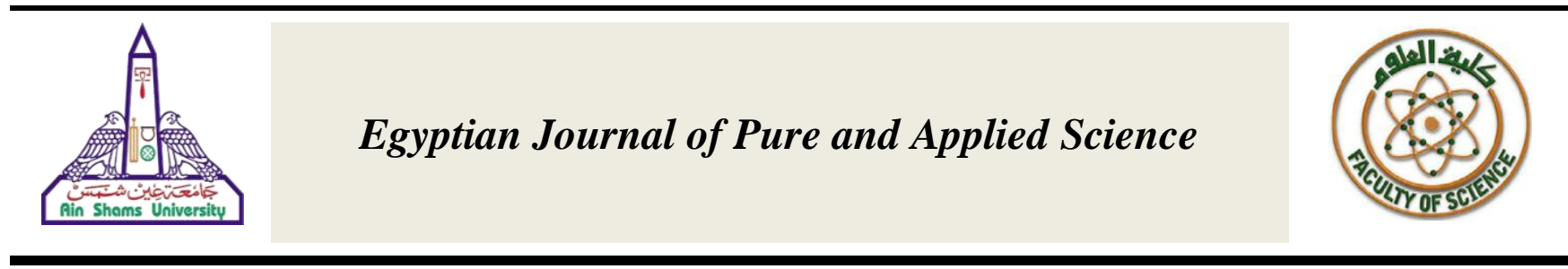

\title{
Utilization of phosphate-waste as a filler material to improve the fertilizers properties
}

\author{
Abd EL-Moneim Osman ${ }^{1}$, Mohamed A. Zaid ${ }^{2}$, Marwa M. Sobeih ${ }^{2}$ and Mohamed F. EL-Shahat ${ }^{3}$ \\ ${ }^{I}$ Department of Geology, Faculty of Science, Ain shams University, Cairo, Egypt, \\ ${ }^{2}$ Abu zaabal Company for Fertilizer and Chemical Company (AZFC), EL-Qalubiaa, Egypt, \\ ${ }^{3}$ Department of Chemistry, Faculty of Science, Ain shams University, Cairo, Egypt.
}

\section{A R T I C L E I N F O}

Article history:

Received 31 August 2013

Accepted 30 September 2013

Keywords:

Phosphogypsum;

Compound fertilizer;

Bentonite clay;

Filler;

Waste disposal.

\begin{abstract}
A B S T R A C T
Phosphogypsum is a waste by-product of wet process of phosphoric acid industry. Usually it was disposed by dumping in large stockpiles in the environment causing serious environmental hazards. It can be successfully used as a filler material in a compound fertilizer (NPK fertilizer) manufacture to improve its properties. A comparative study with bentonite clay filler was done. The main physico-chemical parameters were examined using standard methods. It was noticed that using of phosphogypsum as a filler improves the quality of NPK fertilizers, which notified in terms of physical and chemical characteristics. The results reveal that the yield of marketable fraction becomes sufficient and equals $90.1 \%$ to $92.01 \%$ of the product, while the percentage of the fine particles and the percentage of oversize granules are decreased down to $2.10 \%$ $2.79 \%$ and $5.87 \%-7.11 \%$, respectively. Moreover, the crushing strength is improved up to $2.90 \mathrm{Kg} / \mathrm{g}$. PG filler also demonstrates a desirable chemical characteristic due to its sulfur and calcium content. The improvement in NPK fertilizer quality showed a positive impact of PG on NPK fertilizer industry handin-hand with environmental protection and plant fertilization.
\end{abstract}

\section{Introduction}

In wet-process; the phosphate content of the rock is converted by concentrated sulfuric acid to phosphoric acid and phosphogypsum (PG) by-product. This process is economic; but results in production of large amount of PG waste. Previous study performed by ${ }^{[1]}$ estimated that the total world generation of PG is around $100-280$ million tones/year. Consequently, if historic trends continue, the production will increase to several hundred million metric tons annually. Morphologically, PG is deep yellowish and relatively soft grains formed as a moistured aggregated cake after the filtration process during the phosphoric acid manufacture ${ }^{[2]}$. Chemically it is mainly $\mathrm{CaSO}_{4} \cdot 2 \mathrm{H}_{2} \mathrm{O}$, it consists of $65-70 \%$ calcium sulfate, $25-30 \%$ water and 5-10\% impurities such as free phosphoric acid and its salts, hydrofluoric acid and its compounds, $\mathrm{R}_{2} \mathrm{O}_{3}$, quartz, alkali and organic matter ${ }^{[3]}$. The chemical, physical and mechanical properties of PG aren't only dependent upon the nature of the phosphate ore used but also on other factors such as the type of wet process employed, plant operation efficiency, disposal method, age of cake form-

* Corresponding author.

E-mail address: Osman.moneim@gmail.com ation, location and the depth of the landfill or stack where PG is dumped ${ }^{[4]}$.

The commercial uses of PG are almost without limit especially in the construction industry (building/road construction) and in the agriculture applications (e.g. amelioration of acid soils). PG plays an important role in soil properties and reclamation practices on phosphorous dynamics especially, in calcareous and highly weathered soils, which are characterized by their relatively low exchange capacities and / or low levels of extractable nutrients. It is considered an ideal source of sulfur and calcium. It is slightly soluble in water and, therefore, long-lasting in the soil [5]. A great interest of PG utilization appears as a filler material in many applications as in manufacturing of thermoplastics, preparation of some composite materials used in construction building and decorative purposes [6, 7]. Various fillers are available in fertilizer industry; one of these fillers namely bentonite clay (BC) filler has a distinct role in the improvement of the soil properties and during the fertilizer industry especially for improving the stabilization of fertilizer product under storage and handling conditions ${ }^{[8,9,10]}$. 
The objective of this work is to investigate the effect of PG as a filler material on NPK fertilizer properties. In addition, the work aims to make a comparative study with BC filler.

\section{Materials and Methods}

\section{Raw materials used}

Fertilizer material (FM) such as ammonium sulfate (a product of Suez Company for fertilizers, Egypt), phosphatic fertilizers (concentrated super phosphate (TSP) and single super phosphate (SSP) produced by Abu Zaabal for fertilizers and Chemicals Company (AZFC), Egypt) and potassium chloride (a product of El-Nasr Pharmaceutical and Chemicals Company, Egypt) are used as sources of $\mathrm{N}, \mathrm{P}$ and $\mathrm{K}$ elements, respectively. PG and $\mathrm{BC}$ are used as fillers materials. PG samples are collected from different sites of different formation times from the area of phosphoric acid production in AZFC, these samples are left in atmospheric air for sufficient period (two weeks), and then they are pulverized, homogenized and sieved. BC filler material is introduced by Egypt for NanoTechnology Company; it is homogenized and sieved, then it stored in plastic bags till use.

\section{Preparation of NPK fertilizers:}

Three NPK fertilizers formulas (2: 20: 20), (7: 14:7) and (8: 15: 15) are prepared in AZFC granulation units as shown in Fig.1, each formula is composed of the following three mixture samples:

1. $\mathrm{S}_{1}$ reference samples: $\mathrm{FM}(\mathrm{TSP}+\mathrm{SSP}+\mathrm{KCl}+$ $\left.\left(\mathrm{NH}_{4}\right)_{2} \mathrm{SO}_{4}\right)$ without filler addition.

2. $\mathrm{S}_{2}$ samples: $\mathrm{FM}\left(\mathrm{TSP}+\mathrm{KCl}+\left(\mathrm{NH}_{4}\right)_{2} \mathrm{SO}_{4}\right)+\mathrm{PG}$ filler.

3. $\mathrm{S}_{3}$ samples: $\mathrm{FM}\left(\mathrm{TSP}+\mathrm{KCl}+\left(\mathrm{NH}_{4}\right)_{2} \mathrm{SO}_{4}\right)+\mathrm{BC}$ filler.

The percentage of each FM in each NPK fertilizers formula was calculated according to the percentage of $\mathrm{N}, \mathrm{P}$ and $\mathrm{K}$ in their sources as shown in table 1 .

The nitrogen content in the samples is determined by kjeldahal method using Kjeldahl apparatus model $\mathrm{K}$ $355^{[11]}$, the phosphorus content is determined by color- imetric method using UV-Visible spectrophotometer model UV- $1601^{[11]}$, potassium and sodium content is determined with a flame photometer PFP-7 ${ }^{[11]}$, the calcium ${ }^{[12]}$ and sulfur ${ }^{[11]}$ content is determined by gravimetric method. The atomic absorption spectrometry method is applied for the determination of microelements content using Unicam flame atomic absorption spectrophotometer model Solar-969 ${ }^{[11]}$. Xray radiation diffraction analysis of the prepared samples is carried out by the X-ray diffractometer model Philips PW 3710/31 ${ }^{[13]}$. Physical properties of the samples are evaluated by standard methods since the moisture content is determined by oven-drying method [14], the particle size distribution is measured by conducting a sieve analysis on a representative sample and the granule strength involved determination of the crushing strength of individual granules using Pharma Test Hardness tester model PTB 311E $\mathrm{E}^{[15]}$.

\section{Results and discussion}

\section{Characterization of raw materials:}

The chemical analysis of PG (table 2), showed that the main component of PG is $\mathrm{CaSO}_{4}$ beside some oxides such as silicon, iron and aluminum oxides. Presence of $\mathrm{P}_{2} \mathrm{O}_{5}$ content is attributed to PG origin; as it is the byproduct of wet-process of phosphoric acid production. The data revealed the presence of low concentration of heavy metals (ppm); but it does not exceed the limiting and guidance values. On the other hand, the chemical analysis of BC (table 3), showed that BC contains approximately $55.50 \% \mathrm{SiO}_{2}$ beside some oxides such as iron and aluminum oxides. As it well known, BC has a very high cationic exchange capacity due to its montmorillonite content. The montmorillonite surfaces are populated by oxygen atoms which promote a high degree of reactivity and thus, it can be used as bonding agent for bonding different materials. Therefore, addition of it as a constituent in a combination of materials is helping in developing of the granule rigidity [16]. This diagnostic feature controls the behavior of BC inside the fertilizer granule and yields a very promising result in terms of mechanical properties.

Table 1: Percentage (\%) of each component in one ton of NPK fertilizers samples.

\begin{tabular}{|c|c|c|c|c|c|c|c|}
\hline \multirow{2}{*}{$\begin{array}{c}\text { NPK } \\
\text { formula }\end{array}$} & \multirow[t]{2}{*}{ samples } & \multirow{2}{*}{$\begin{array}{c}\text { Amm. Sulfate } \\
(\%)\end{array}$} & \multirow[t]{2}{*}{$\operatorname{TSP}(\%)$} & \multirow[t]{2}{*}{$\operatorname{SSP}(\%)$} & \multirow{2}{*}{$\begin{array}{c}\text { Potassium } \\
\text { chloride } \\
(\%)\end{array}$} & \multicolumn{2}{|c|}{ Filler } \\
\hline & & & & & & $\begin{array}{l}\text { PG } \\
(\%)\end{array}$ & $\begin{array}{c}\text { BC } \\
(\%) \\
\end{array}$ \\
\hline \multirow[t]{3}{*}{2.20 .20} & $S_{1}$ & $9.50 \%$ & $35.80 \%$ & $21.40 \%$ & $33.30 \%$ & ------ & ------- \\
\hline & $\mathbf{S}_{2}$ & $9.50 \%$ & $44.40 \%$ & --------- & $33.30 \%$ & $12.80 \%$ & ------- \\
\hline & $\mathbf{S}_{3}$ & $9.50 \%$ & $44.40 \%$ & ---------- & $33.30 \%$ & ------- & $12.80 \%$ \\
\hline \multirow[t]{3}{*}{7.14 .7} & $S_{1}$ & $33.30 \%$ & $15.00 \%$ & $40.10 \%$ & $11.60 \%$ & ------- & ------- \\
\hline & $\mathbf{S}_{2}$ & $33.30 \%$ & $31.00 \%$ & -------- & $11.60 \%$ & $24.00 \%$ & ------- \\
\hline & $S_{3}$ & $33.30 \%$ & $31.00 \%$ & -------- & $11.60 \%$ & ------- & $24.00 \%$ \\
\hline \multirow[t]{3}{*}{8.15 .15} & $\mathbf{S}_{1}$ & $38.00 \%$ & $30.90 \%$ & $6.10 \%$ & $25.00 \%$ & $\begin{array}{l}------ \\
\end{array}$ & -------- \\
\hline & $\mathbf{S}_{2}$ & $38.00 \%$ & $33.30 \%$ & -------- & $25.00 \%$ & $3.70 \%$ & -------- \\
\hline & $\mathbf{S}_{3}$ & $38.00 \%$ & $33.30 \%$ & -------- & $25.00 \%$ & -------- & $3.70 \%$ \\
\hline
\end{tabular}


Table2. Chemical analysis of PG sample

\begin{tabular}{|c|c|}
\hline $\mathbf{I t e m}$ & wt.\% \\
\hline $\mathbf{S i O}_{\mathbf{2}}$ & 3.70 \\
\hline $\mathbf{C a O}$ & 26.0 \\
\hline $\mathbf{S O}_{\mathbf{3}}$ & 37.0 \\
\hline $\mathbf{P}_{\mathbf{2}} \mathbf{O}_{\mathbf{5}}$ & 1.90 \\
\hline $\mathbf{M g O}$ & 0.35 \\
\hline $\mathbf{F e}_{\mathbf{2}} \mathbf{O}_{\mathbf{3}}$ & 0.21 \\
\hline $\mathbf{A l}_{\mathbf{2}} \mathbf{O}_{\mathbf{3}}$ & 0.09 \\
\hline $\mathbf{M n O}$ & 0.03 \\
\hline $\mathbf{K}_{\mathbf{2}} \mathbf{O}$ & 0.004 \\
\hline $\mathbf{N a}_{\mathbf{2}} \mathbf{O}$ & 0.09 \\
\hline $\mathbf{F}$ & 0.32 \\
\hline $\mathbf{H}_{\mathbf{2}} \mathbf{O}_{\text {Free }}$ & 15.00 \\
\hline $\mathbf{T r a c e}$ elements ( ppm ) \\
\hline $\mathbf{C u}$ & 5.00 \\
\hline $\mathbf{A s}$ & 0.20 \\
\hline $\mathbf{C d}$ & 0.80 \\
\hline $\mathbf{N i}$ & 6.70 \\
\hline $\mathbf{Z n}$ & 6.50 \\
\hline $\mathbf{P b}$ & 5.50 \\
\hline
\end{tabular}

Table3. Chemical composition of BC

\begin{tabular}{|c|c|}
\hline Item & wt.\% \\
\hline $\mathrm{SiO}_{2}$ & 55.50 \\
\hline $\mathrm{CaO}$ & 0.50 \\
\hline $\mathrm{SO}_{3}$ & 0.28 \\
\hline $\mathbf{P}_{2} \mathbf{O}_{5}$ & 0.08 \\
\hline MgO & 1.53 \\
\hline $\mathrm{Fe}_{2} \mathrm{O}_{3}$ & 5.89 \\
\hline $\mathrm{Al}_{2} \mathrm{O}_{3}$ & 20.89 \\
\hline $\mathbf{K}_{2} \mathbf{O}$ & 1.05 \\
\hline $\mathrm{Na}_{2} \mathrm{O}$ & 0.35 \\
\hline \multicolumn{2}{|c|}{ Trace element content (ppm) } \\
\hline $\mathbf{C u}$ & 40.00 \\
\hline $\mathbf{Z n}$ & 82.00 \\
\hline $\mathbf{N i}$ & 38.00 \\
\hline
\end{tabular}

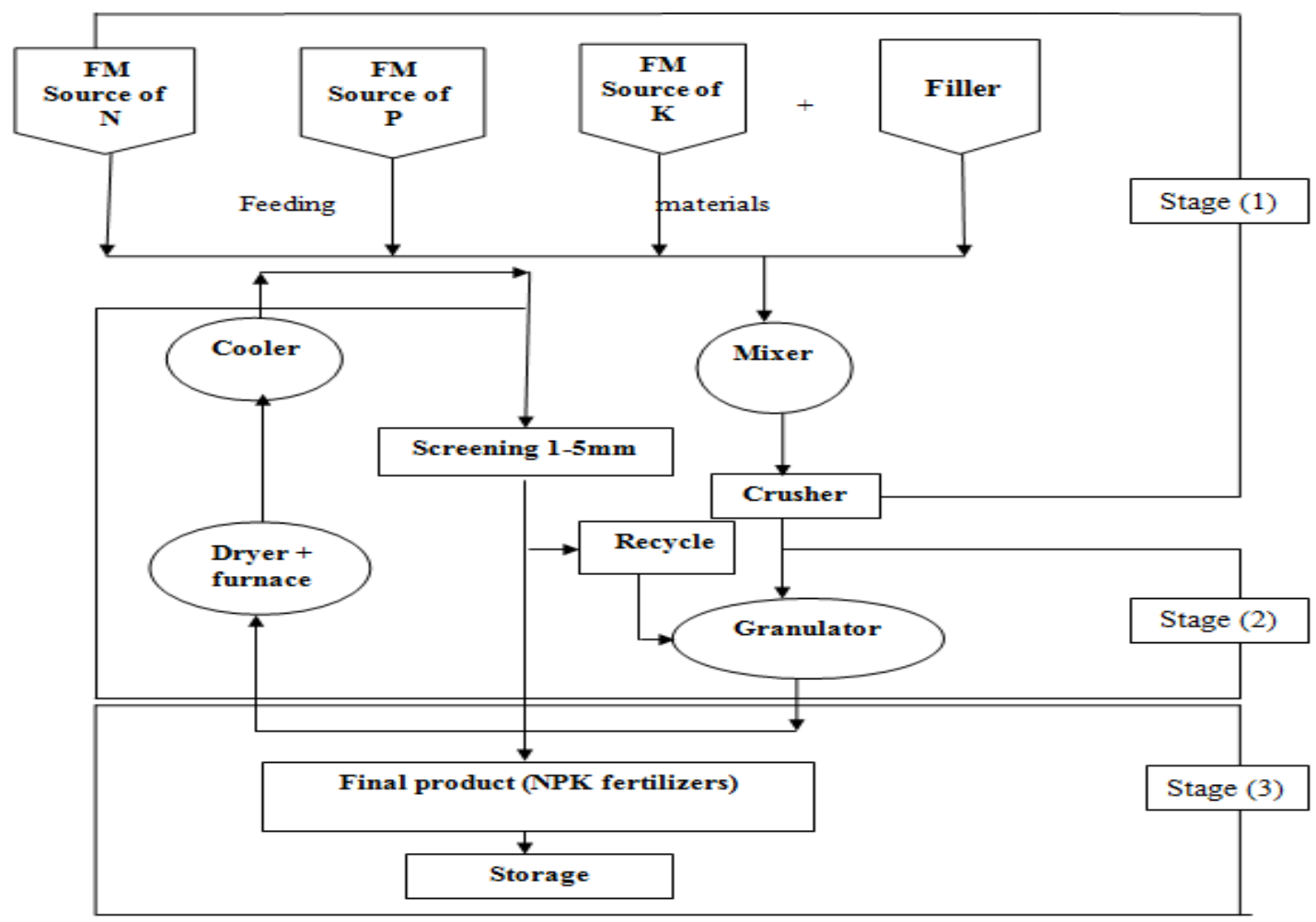

Fig. 1: Flow chart of manufacturing process of NPK fertilizer

Stage (1): Includes mixing of all components of NPK fertilizers in the blender until they became homogeneous.

Stage (2): Includes four steps: $\mathbf{1}^{\text {st }}$ : The granulation process using a granulator which is a rotary drum causes the small particles to agglomerate into granules $2^{\text {nd }}$ : The granules after the process of granulation are fed to the dryer where substantially all of the water remaining in the product is driven off by the heat of reaction through steam outlet $\mathbf{3}^{\text {rd }}$ : The granules are conveyed to cooler where the product is cooled to room temperature $4^{\text {th }}$ : The granules are conveyed to screens where granules of the desired size are selected. The granules which are either too large or too small are conveyed to granulator for proper sizing.

Stage (3): Includes the obtainment of granulated NPK fertilizers. Finally, they are conveyed to storage. 


\section{Characterization of the prepared NPK fertilizer:}

All the prepared NPK fertilizers formulas are characterized in terms of chemical and physical analysis using different granules spectroscopic analysis. For comparison, table (4) includes typical major elements composition of NPK fertilizer prepared under the same processes (preparation and granulation). The obtained results indicated that the three mixed samples in each formula have scarcely the same percentage of N, P and $\mathrm{K}$. While the percentage of sulfur and calcium contents showed wide variation. The reason is attributed to the percentage of sulfur and calcium in SSP and fillers used in these NPK fertilizers productions. The results showed that the percentage of sulfur and calcium contents determined in NPK fertilizers containing PG filler $\left(\mathrm{S}_{2}\right)$ is in good accordance with the percentage obtained from the reference NPK fertilizers $\left(\mathrm{S}_{1}\right)$. Their values ranged from $5.37 \%$ to $8.53 \%$ and $5.42 \%$ to $12.53 \%$ for calcium and sulfur, respectively. On contrary, NPK fertilizers containing BC filler, their sulfur and calcium contents are decreased down to values ranged from 4.44 $\%$ to $6.31 \%$ and $3.51 \%$ to $10.13 \%$ for calcium and sulfur, respectively. These results confirmed that PG plays the similar role of SSP in addition of vital elements needed for soil fertility.

In order to reveal the exact mineralogical composition of NPK fertilizer containing fillers; X-ray powder diffraction analysis is carried out. The X-ray diffraction curve (figure 10) of the NPK fertilizer containing PG filler revealed the presence of two main peaks which are corresponding to anhydrite and potassium chloride at diffraction angles of $28.37(\mathrm{~d}=3.14 \AA)$ and $28.22(\mathrm{~d}=$ $3.15 \AA$ ), respectively. Whereas, the two peaks at diffraction angles of $(\mathrm{d}=3.35 \AA),(\mathrm{d}=3.49 \AA)$ are characterized to quartz and calcium sulfate as the phase composition of the PG waste. Such composition is in a good consistence with its chemical major constituents as reported by ${ }^{[17]}$. The other weak peaks at diffraction angles of $21.99(\mathrm{~d}=4.03 \AA), 40.50(\mathrm{~d}=2.22 \AA), 29.59$ $(\mathrm{d}=3.01 \AA), 31.68(\mathrm{~d}=2.82 \AA)$ and $23.71(\mathrm{~d}=3.75 \AA)$ are attributed to the presence of minor phases such as quartz, clay minerals, calcite, apatite and ammonium phosphate, respectively. Presence of calcite indicates the reactivity of phosphate rock, which influenced strongly by the extent of carbonate substitution for phosphate in the apatite minerals ${ }^{[18,19]}$. The previous data of XRD analysis confirmed that the main phase composition of PG associated with the wet processing of phosphate rock is calcium sulfate ${ }^{[20]}$.

The X-ray diffraction curve (fig.11), showed clearly that the predominant peak at diffraction angle of $28.33(\mathrm{~d}=$ $3.15 \AA$ ) is corresponding to the clay minerals and potassium chloride. Whereas, the other weak peaks at diffraction angles of $21.00(\mathrm{~d}=4.22 \AA), 25.38(\mathrm{~d}=3.50$ $\AA), 29.51(\mathrm{~d}=3.02 \AA)$ and $31.39(\mathrm{~d}=2.84 \AA)$ are attributed to the presence of other phases such as quartz, calcium sulfate, calcite and apatite, respectively. The previous data of XRD analysis confirmed that the main phase composition of $\mathrm{BC}$ is clay minerals; such composition is in a good consistence with its chemical major constituents as reported by ${ }^{[21]}$.

On the other hand, the results of the mechanical properties examinations of these NPK fertilizers showed uniformity in its compositions. This uniformity is observed in the reduction of the percentage of the fine and the oversize particles as well as increasing the percentage of marketable fraction. Figures (2), (3), (4) and (5) showed that PG is capable of improving the granulometric composition of these prepared fertilizers; since the yield of marketable fraction $(2-5 \mathrm{~mm})$ is sufficient and ranged from $90.1 \%$ to $92.01 \%$ of the product, while the percentage of the fine particles $(<$ $2 \mathrm{~mm}$ of diameter) and the percentage of oversize granules (> 5mm of diameter) are decreased down to values ranging from $2.10 \%$ to $2.79 \%$ and from $5.87 \%$ to $7.11 \%$, respectively. Moreover, PG showed a positive impact on the crushing strength of the fertilizer granule; it gives values ranged from $2.7 \mathrm{~kg} / \mathrm{g}$ to $2.90 \mathrm{~kg} / \mathrm{g}$. These values are sufficient compared to values ranged from 2.0 $\mathrm{kg} / \mathrm{g}$ to $2.1 \mathrm{~kg} / \mathrm{g}$ of the initial reference samples. Similar results of fraction distribution are obtained when $\mathrm{BC}$ filler is used. It was found that the crushing strength values of these NPK fertilizers containing BC filler are ranged from $3.1 \mathrm{~kg} / \mathrm{g}$ to $3.35 \mathrm{~kg} / \mathrm{g}$ and the yield of marketable fraction is ranged from $91 \%$ to $93.11 \%$ of the product, whereas the percentage of the fine particles and the percentage of oversize granules are ranged from $1.89 \%$ to $2.99 \%$ and from $3.90 \%$ to $7.11 \%$, respectively. Consequently, these results indicated that PG plays the similar role of BC on improving the physical properties of NPK fertilizer. It should be mentioned that the uniformity of NPK fertilizer composition is considered an important factor in reducing the caking tendency between fertilizer granules, where the specific surface area of the granules is reduced and consequently, the forces of attraction and the points of contacts between the adjacent granules are also reduced.

The morphological texture of NPK fertilizer, as examined by optical microscope, illustrated in figure (12) showed two different sections of internal part component of NPK fertilizer granule containing PG filler. The photomicrographs reveal a homogeneous and prismatic PG piling arrangement forming tables structure (figure 12a ) and a well-defined crystalline structure with a majority of circular shaped crystals (figure $12_{b}$ ). The structures of PG crystals filling the inner spaces indicated that $\mathrm{PG}$ is more admixed with the other phases forming a more complicated composition. Such complication was shown to help in improving the micro-structural continuity and consequently, improving the mechanical properties of these NPK fertilizer. On the other hand figure (13) showed two different sections of internal part component of NPK fertilizer granule containing BC filler. The photomicrographs showed the presence of aggregates of Montmorillonite platelets. 
Figure $\left(13_{\mathrm{a}}\right)$, showed the inhomogeneous distribution of clay dispersion in the internal part of fertilizer granule; where this clay appears in different sizes of aggregates with irregular or hexagonal flakes or less commonly, of thin laths inside the fertilizer granule ${ }^{[22]}$. Figure $\left(13_{b}\right)$, showed coarser microcrystal aggregates, which make an intercalation with other FM in some parts filling the internal free pores. Such clay dispersion was shown to yield a very promising result in terms of mechanical properties. In some internal part sections of NPK fertilizer containing fillers (figure 14), the aggregates of calcite, which well defined by its light birefringence was observed. Its formation is attributed to the reaction of phosphate rock with sulfuric acid to produce gypsum and carbon dioxide. This reaction may be happened if the phosphate rock used in production of concentrated super phosphate (source of phosphorus nutrient in this study) contains carbonate ${ }^{[18,19]}$.

Generally, NPK fertilizer using PG or BC fillers is prepared and granulated under the same conditions, therefore there's no significant difference in the structure of the outer rim of fertilizer granule. The photomicrograph (fig. 15), showed the external part with micro pores in all the surface of fertilizer granule.

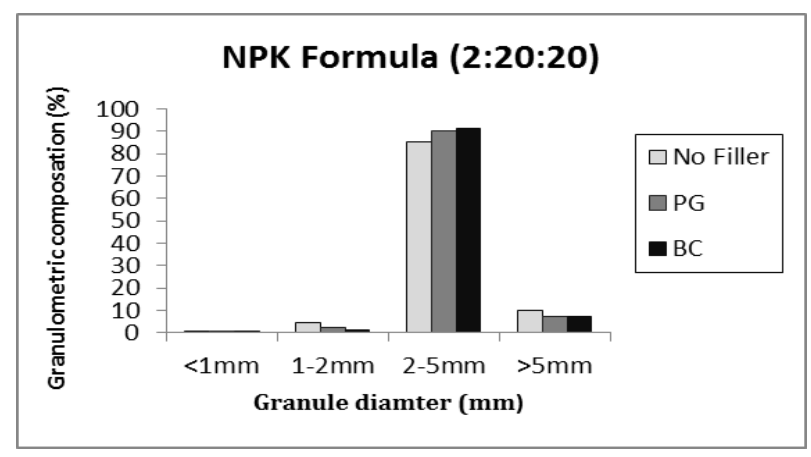

Fig. 2: Relation between granulometric composition and each granule diameter of NPK fertilizer.

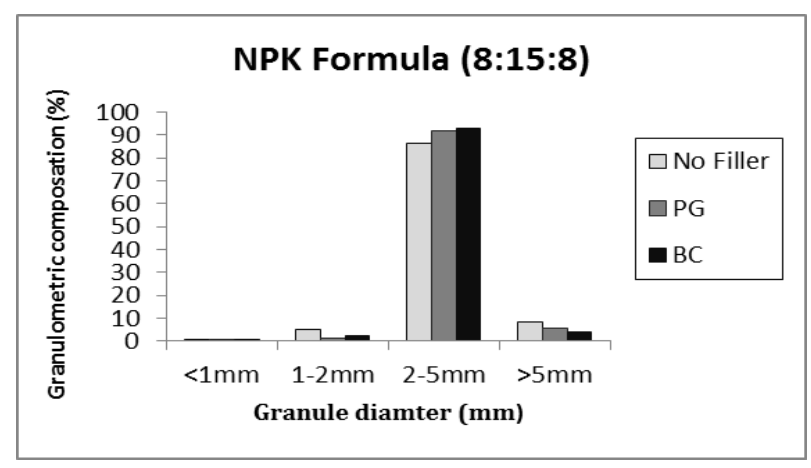

Fig. 4: Relation between granulometric composition and each granule diameter of NPK fertilizer.
Presence of these micro pores is due to the exit of air from the granule during the granulation process.

\section{Conclusions}

PG is an industrial waste from phosphoric acid industrial process. Its chemical composition is suitable to be used as filler material like BC filler in manufacturing of NPK fertilizer containing nitrogen, phosphorus and potassium nutrients. The advantages of using PG as filler in these NPK fertilizers are summarized in improving its physical properties such as the granulometry and the strength of granules. Additions of PG filler can helping in producing NPK fertilizers with high quality; refers to hard, spherical and noncaking product and consequently, it resulted in a high mechanical hardness of fertilizer granules that will be sufficient under storage and handling conditions compared to the usual NPK fertilizer. A great interest of using PG as filler not only appears in minimizing both industrial productivity loss and atmospheric pollution or reduction of the main phosphate product price via utilization of cheap filler like PG; but also appears in its role as an excellent fertilizer source of sulfur and calcium.

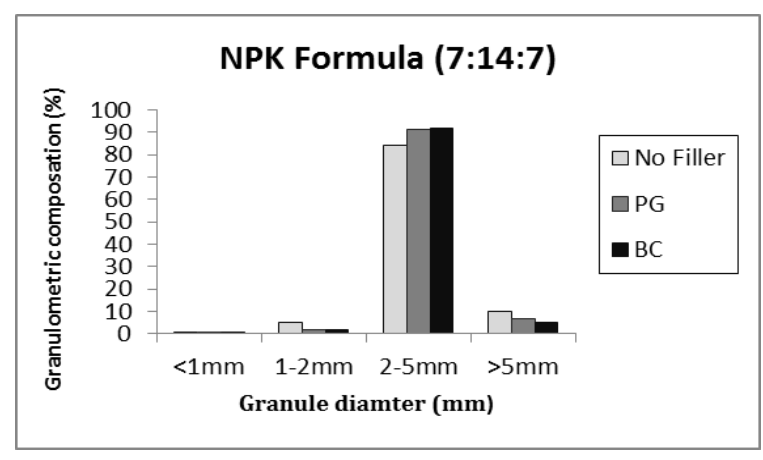

Fig. 3: Relation between granulometric composition and each granule diameter of NPK fertilizer.

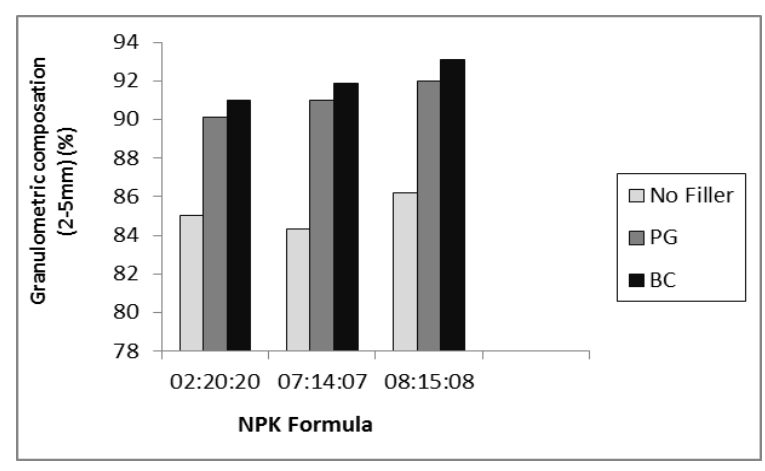

Fig. 5: Variation in the precentage of granulometric composition of the market size granules for different NPK fertilizer formules. 
Table 4: Major elements composition of NPK fertilizer (wt. \%).

\begin{tabular}{|c|c|c|c|c|c|c|}
\hline $\begin{array}{c}\text { NPK fertilizers } \\
\text { formulas }\end{array}$ & Mix. samples & $\mathbf{N}$ & $\mathbf{P}$ & $\mathbf{K}$ & $\mathbf{C a}$ & $\mathbf{S}$ \\
\hline \multirow{4}{*}{$\mathbf{2 . 2 0 . 2 0}$} & $\mathbf{S}_{\mathbf{1}}$ & 2.00 & 20.00 & 20.00 & 8.86 & 5.66 \\
\cline { 2 - 7 } & $\mathbf{S}_{\mathbf{2}}$ & 2.00 & 20.00 & 20.00 & 8.53 & 5.42 \\
\cline { 2 - 7 } & $\mathbf{S}_{\mathbf{3}}$ & 2.00 & 20.00 & 19.96 & 6.31 & 3.51 \\
\hline \multirow{4}{*}{$\mathbf{7 . 1 4 . 7}$} & $\mathbf{S}_{\mathbf{1}}$ & 7.00 & 14.00 & 7.00 & 9.32 & 12.95 \\
\cline { 2 - 7 } & $\mathbf{S}_{\mathbf{2}}$ & 7.00 & 14.01 & 7.00 & 8.68 & 12.53 \\
\cline { 2 - 7 } & $\mathbf{S}_{\mathbf{3}}$ & 7.00 & 14.00 & 7.00 & 4.44 & 8.96 \\
\hline \multirow{3}{*}{$\mathbf{8 . 1 5 . 1 5}$} & $\mathbf{S}_{\mathbf{1}}$ & 8.00 & 15.00 & 15.00 & 5.42 & 10.74 \\
\cline { 2 - 7 } & $\mathbf{S}_{\mathbf{2}}$ & 8.00 & 15.00 & 15.00 & 5.37 & 10.69 \\
\cline { 2 - 7 } & $\mathbf{S}_{\mathbf{3}}$ & 8.00 & 15.00 & 15.00 & 4.70 & 10.13 \\
\hline
\end{tabular}

$* \mathrm{P}$ is calculated as $\mathrm{P}_{2} \mathrm{O}_{5}$

$* \mathrm{~K}$ is calculated $\operatorname{asK}_{2} \mathrm{O}$

Table 5: Results of physical properties of NPK fertilizer (Moisture content and granulmetric composition).

\begin{tabular}{|c|c|c|c|c|c|c|}
\hline NPK formulas & \multirow{2}{*}{$\begin{array}{c}\text { Mix. Samples } \\
\text { No. }\end{array}$} & \multirow{2}{*}{$\begin{array}{c}\text { Moisture } \\
\text { content } \\
(\boldsymbol{\%})\end{array}$} & \multicolumn{3}{|c|}{ Granulometric composition (\%) } \\
\cline { 4 - 7 } & & 2.90 & $<\mathbf{m m}$ & $\mathbf{1 - 2 m m}$ & $\mathbf{2 - 5 m m}$ & $>\mathbf{5 m m}$ \\
\hline \multirow{3}{*}{$\mathbf{2 . 2 0 . 2 0}$} & $\mathbf{S}_{\mathbf{1}}$ & 2.89 & 0.68 & 4.47 & 85.00 & 10.12 \\
\cline { 2 - 7 } & $\mathbf{S}_{\mathbf{2}}$ & 2.70 & 0.55 & 1.34 & 91.00 & 7.11 \\
\cline { 2 - 7 } & $\mathbf{S}_{\mathbf{3}}$ & 2.80 & 0.66 & 4.88 & 84.35 & 10.11 \\
\hline \multirow{4}{*}{$\mathbf{7 . 1 4 . 7}$} & $\mathbf{S}_{\mathbf{1}}$ & 2.74 & 0.34 & 1.76 & 91.00 & 6.90 \\
\cline { 2 - 7 } & $\mathbf{S}_{\mathbf{2}}$ & 2.50 & 0.80 & 2.00 & 91.90 & 5.30 \\
\hline \multirow{3}{*}{$\mathbf{8 . 1 5 . 1 5}$} & $\mathbf{S}_{\mathbf{3}}$ & 3.11 & 0.54 & 5.04 & 86.22 & 8.20 \\
\cline { 2 - 7 } & $\mathbf{S}_{\mathbf{1}}$ & 2.90 & 0.66 & 1.46 & 92.01 & 5.87 \\
\cline { 2 - 7 } & $\mathbf{S}_{\mathbf{2}}$ & 2.86 & 0.54 & 2.45 & 93.11 & 3.90 \\
\hline
\end{tabular}

Table 6: Results of physical properties (crushing strength) of NPK fertilizer.

\begin{tabular}{|c|c|c|c|c|c|c|}
\hline \multirow[t]{2}{*}{ NPK formulas } & \multirow[t]{2}{*}{$\begin{array}{l}\text { Mix. Samples } \\
\text { No. }\end{array}$} & \multirow{2}{*}{$\begin{array}{c}\text { Mean crushing } \\
\text { strength of } \\
\text { samples (Kg/g) }\end{array}$} & \multicolumn{4}{|c|}{$\begin{array}{c}\text { Crushing strength } \\
(\mathrm{Kg} / \mathrm{g})\end{array}$} \\
\hline & & & $<1 \mathrm{~mm}$ & $1-2 \mathrm{~mm}$ & $2-5 \mathrm{~mm}$ & $>5 \mathrm{~mm}$ \\
\hline \multirow{3}{*}{2.20 .20} & $\mathbf{S}_{1}$ & 2.00 & 0.00 & 1.10 & 2.0 & 2.48 \\
\hline & $\mathbf{S}_{2}$ & 2.80 & 0.00 & 1.80 & 2.82 & 3.12 \\
\hline & $\mathbf{S}_{3}$ & 3.10 & 0.00 & 1.40 & 3.13 & 3.28 \\
\hline \multirow{3}{*}{7.14 .7} & $\mathbf{S}_{1}$ & 2.10 & 0.00 & 1.05 & 2.13 & 2.50 \\
\hline & $\mathbf{S}_{2}$ & 2.90 & 0.00 & 1.30 & 2.93 & 3.11 \\
\hline & $\mathbf{S}_{3}$ & 3.35 & 0.00 & 1.35 & 3.40 & 3.78 \\
\hline \multirow{3}{*}{ 8.15.15 } & $\mathbf{S}_{1}$ & 2.10 & 0.00 & 0.90 & 2.10 & 3.00 \\
\hline & $\mathbf{S}_{2}$ & 2.70 & 0.00 & 1.39 & 2.70 & 3.33 \\
\hline & $\mathbf{S}_{3}$ & 3.25 & 0.00 & 1.35 & 3.30 & 3.70 \\
\hline
\end{tabular}




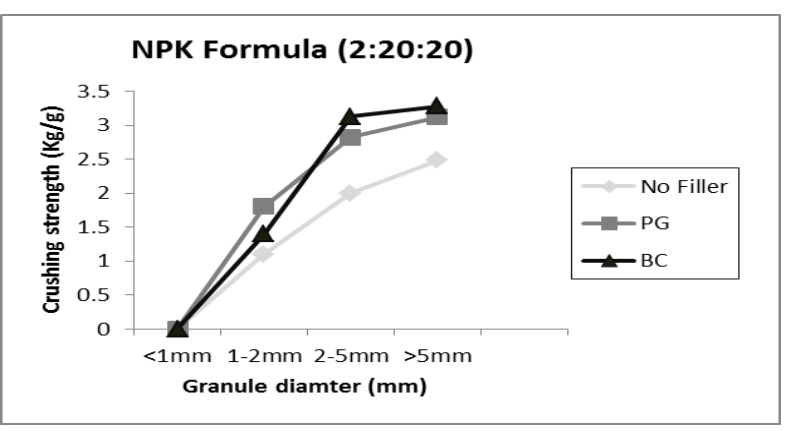

Fig. 6: Dependence of the crushing strength value on the diameter of NPK fertilizer granule for 2:20:20 formula.

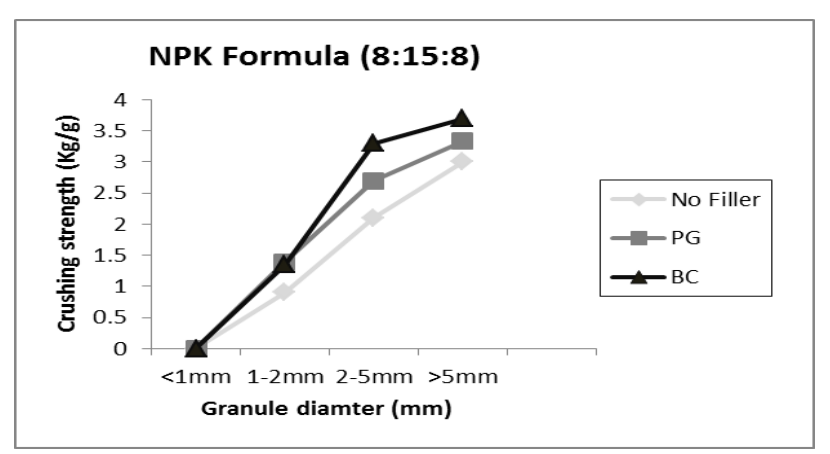

Fig. 8: Dependence of the crushing strength value on the diameter of NPK fertilizer granule for 8:15:15 formula.

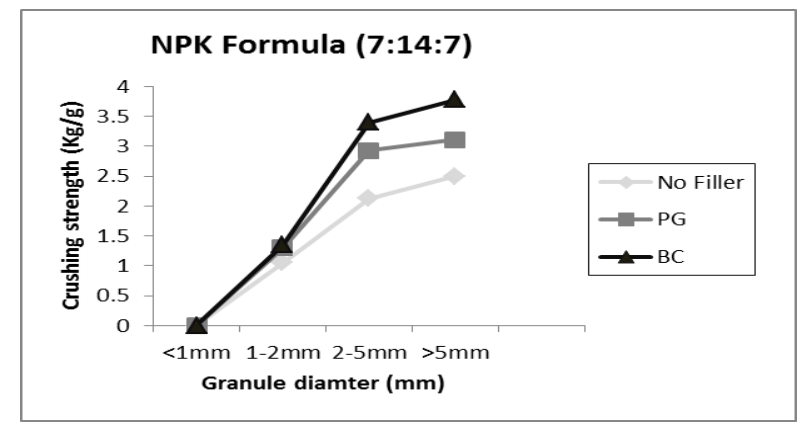

Fig. 7: Dependence of the crushing strength value on the diameter of NPK fertilizer granule for 7:14:7 formula.

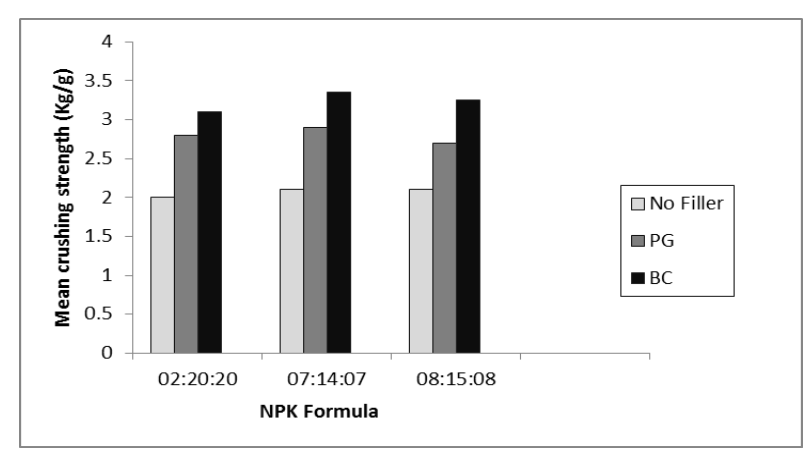

Fig. 9: Effect of fillers (PG and $B C$ ) on the improvement of crushing strength for different NPK fertilizer formula.

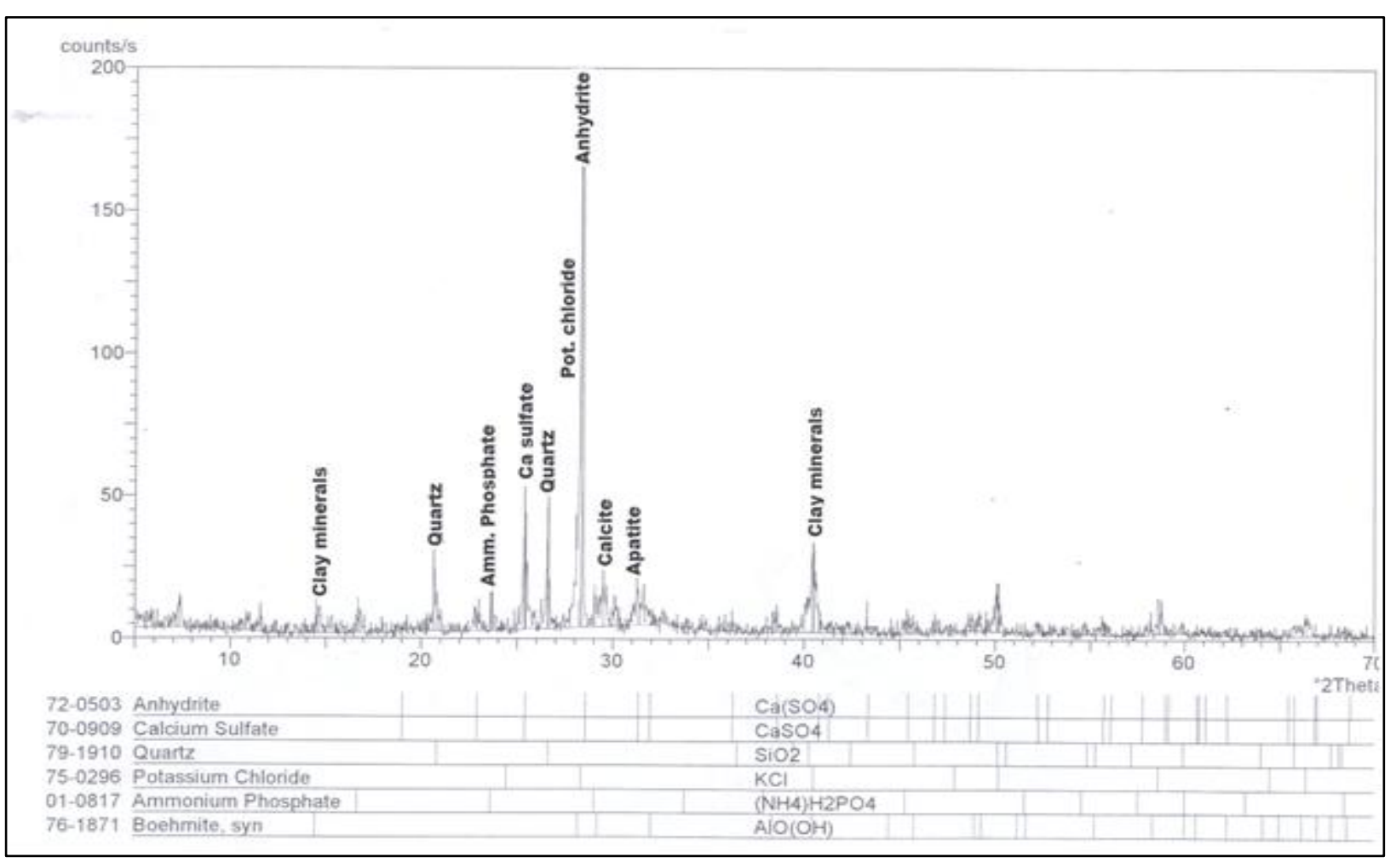

Fig. 10: X-ray diffraction curve for NPK fertilizer containing PG filler. 


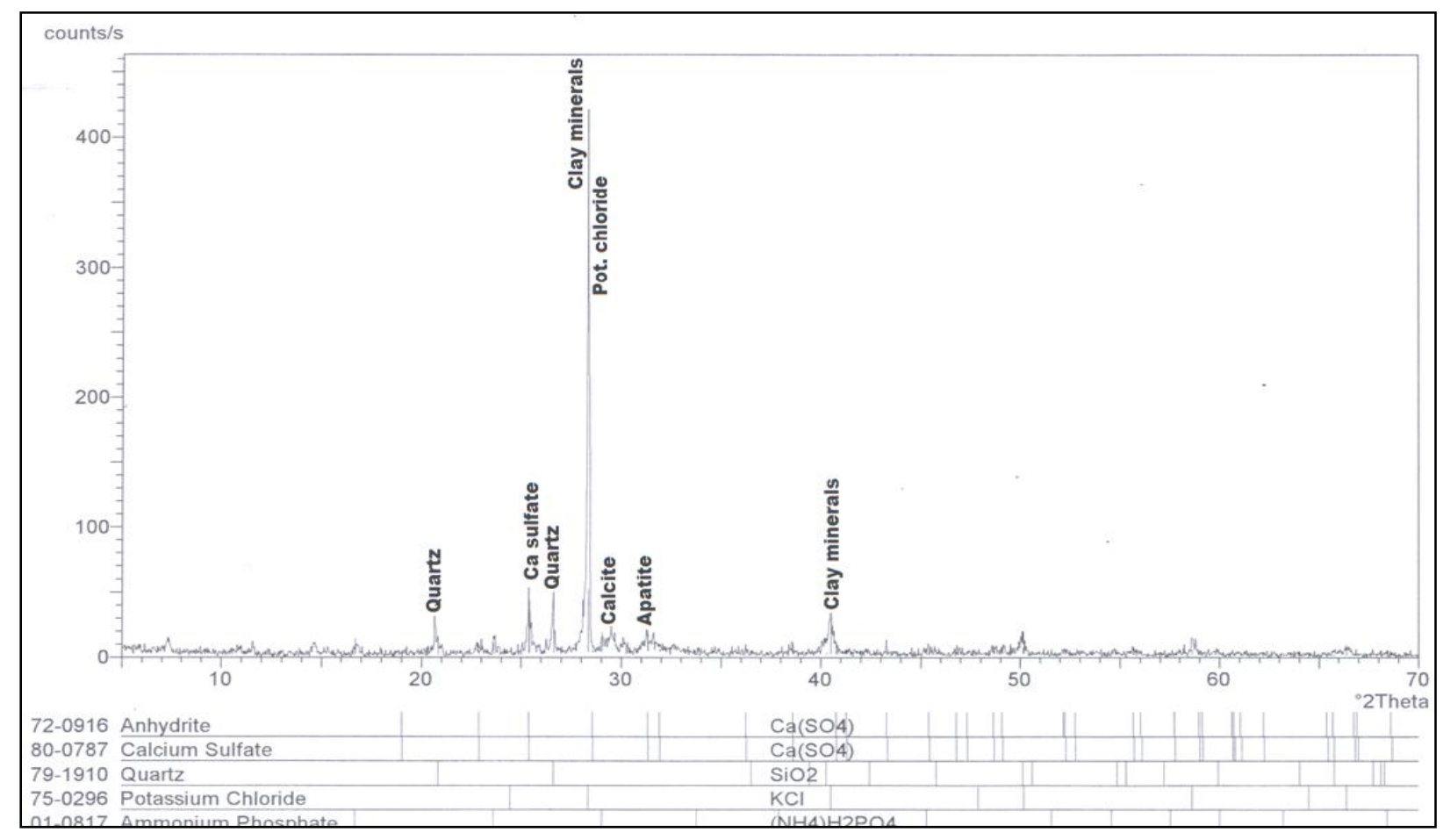

Fig. 11: X-ray diffraction curve for NPK fertilizer containing BC filler.

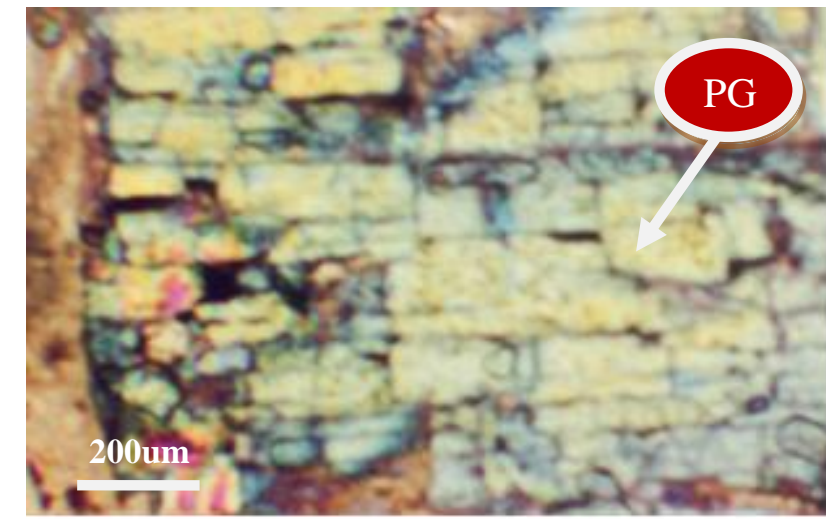

Fig. 12a: Microphotograph of thin section of the internal part of NPK fertilizer showing the table's structure of PG filler.

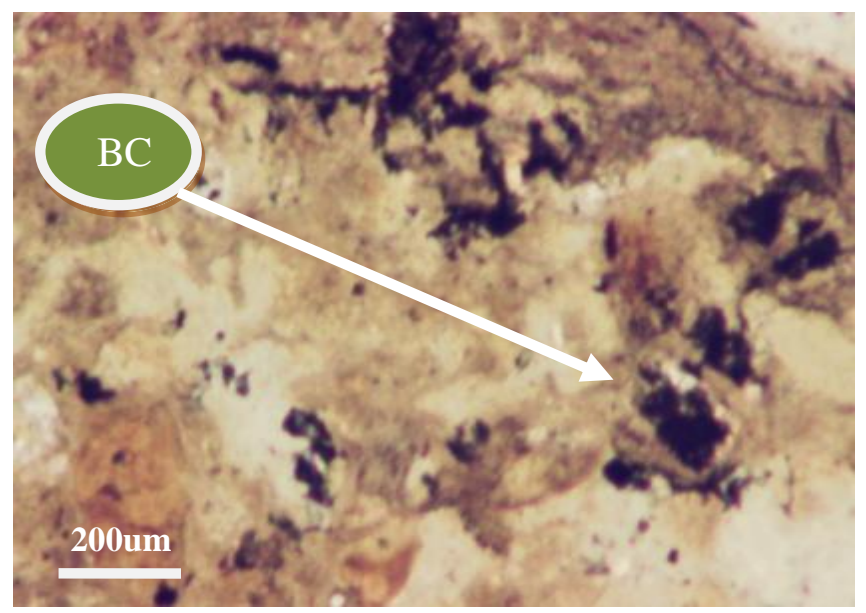

Fig. 13a: Microphotograph of thin section of NPK fertilizer containing $\mathrm{BC}$ filler showing the internal part with micro-grains of $\mathrm{BC}$ filler.

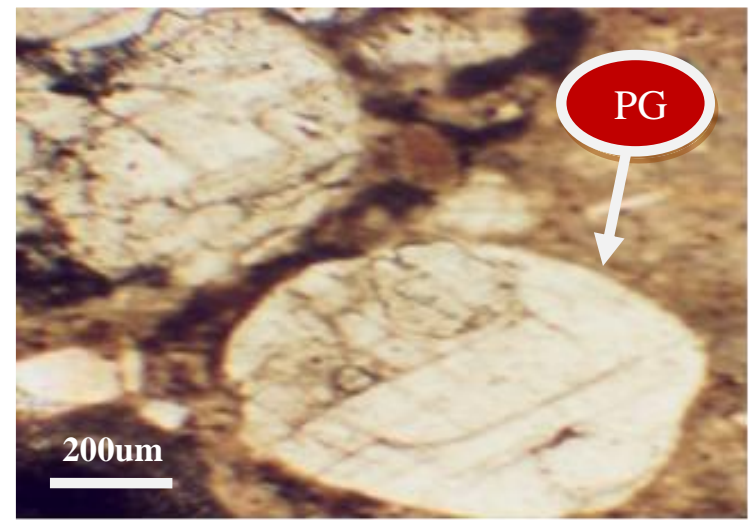

Fig. 12b: Microphotograph of thin section of the internal part of NPK fertilizer showing the rounded microcrystal structure of PG filler.

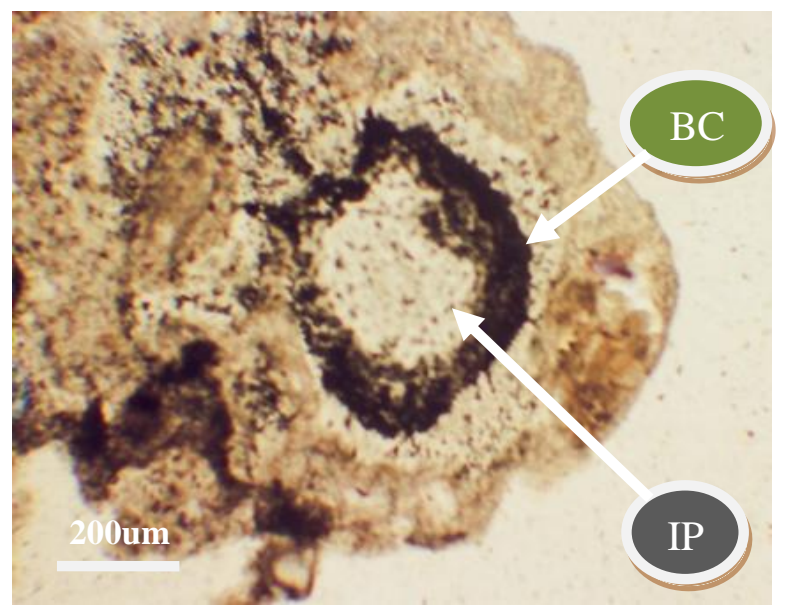

Fig. 13b: Microphotograph of thin section of NPK fertilizer containing BC filler showing the internal Pores (IP) filled with BC grains. 


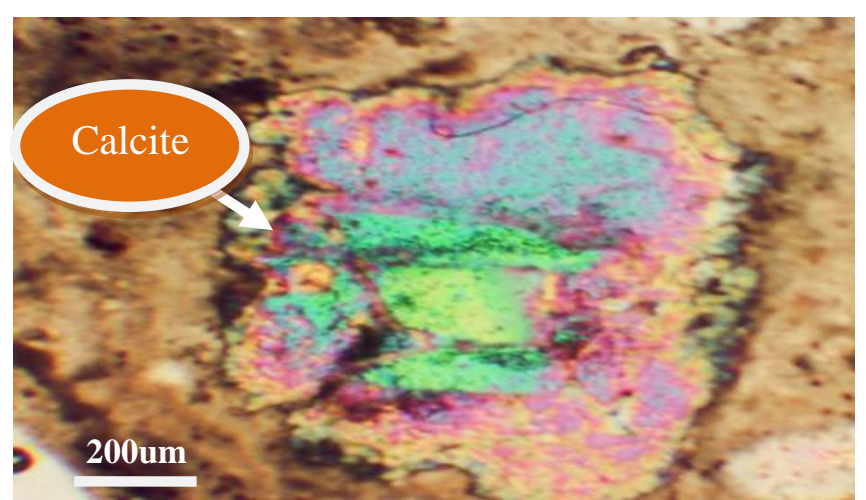

Fig. 14: Microphotograph of thin section of the internal part of NPK fertilizer containing filler showing calcite aggregates.

\section{References}

1) Tayibi H., Choura M., Lopez F., Alguacil F. and Delgado A. (2009). Environmental impact and management of phosphogypsum, Journal of Environmental Management, Elsevier, 90: 23772386.

2) Jackson M. (2009). Assessment of soil capping for phosphogypsum stack reclamation at fort Saskatchewan, Alberta, unpublished M.Sc. Thesis, Alberta, Canada University, , 162.

3) Kaziliunaws A., Leskeviciene V., Vektaris B. and Valancius Z. (2006). The study of neutralization of the dihydrate phosphogypsum impurities, Journal of Ceramics-Silikaty, 3: 178-184.

4) Arman A. and Seals R.K., (1990). A preliminary assessment of utilization alternatives for phosphogypsum, In: Chang, W.E., (Ed.), Proceeding of the $3^{\text {rd }}$ International Symposium on Phosphogypsum, Florida institute of Phosphate research, Bartow, Florida, pp 562-583.

5) Michael G.L. (1985). Phosphogypsum, Florida Institute of Phosphate Research, Bartow Florida, pp 2-14.

6) Kowalska E. and Kawinska B. (2002). The use of Phosphogypsum as a filler for thermoplastics, Part II: phosphogypsum as a filler for Polyamide 6 and for PVC. J Reinforced Plastics and Composites 21: 1043-1052.

7) Hanna A.A. (2000). Abu- Ayana Y.M. and Ahamed S.M., Phosphogypsum Utilization, part III: As Adhesive Filler and Composite Materials, Journal of Mater. Sci. Technol. 16: 427.

8) Chisholm F. (1960). Bentonite in industry, Mines Magazine, pp 30- 42.

9) Ampian S.G. (1985). Clays, in Mineral facts and problems, U.S., Bureau of Mines, Bulletin (675), pp 157-169.

10) Inglethorpe S., Morgan D., Highley D. and Blood w. (1993). Bentonite. Industrial Minerals Laboratory Manual, pp 13-15.

11) Association of Official Analytical Chemist, Official Methods of Analysis, EUA, (2000).

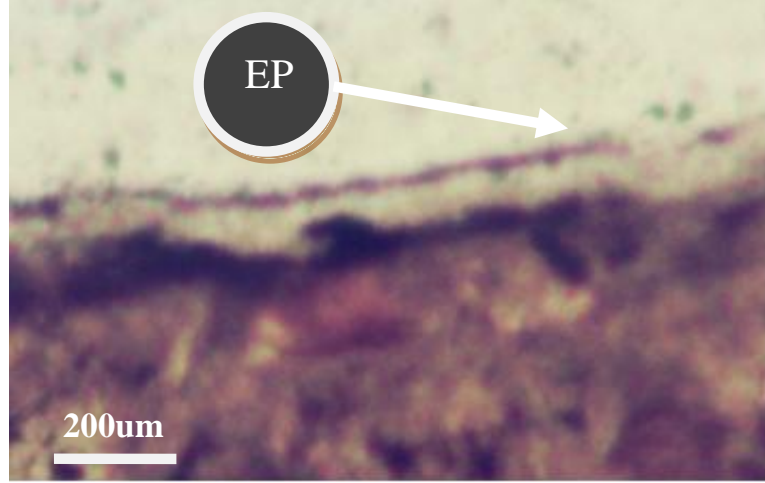

Fig. 15: Microphotograph of thin section of the external part of NPK fertilizer containing filler showing the external pores (EP) in the outer rim of the granule.

12) Vogel's textbook of Bassett J., Denny R.C., Jeffery G.H. and Mendham j. (1982). English Language Book Society (ELBS), Quantitative inorganic analysis.

13) Norish K. and Chappell B. W. (1977). X-ray fluorescence spectrometry. In: Zussman, J. (Ed.), Physical Methods in Determinative mineralogy, $2^{\text {nd }}$ Ed. Academic Press, London, pp 201-272.

14) Egyptian Organization for Standardization and Quality (2005). The Official Methods of analysis, pp 7.

15) United Nations Industrial Development organization (UNIDO) (1967). Fertilizer Manual, pp 284- 484.

16) Onal M. (2006). Physicochemical properties of Bentonites, An overview, Commun Faculty of Science, Ankara University, Series B, 52:7-21.

17) El-Gamal E. (2007). Studies on the treatment of solid wastes produced during purification of phosphoric acid at phosphoric acid purification pilot plant, Nuclear Materials Authority (NMA), unpublished M.Sc. Thesis, Al-Azhar University, Egypt.

18) Bolan N.S., Hedley M.J. and Loganathan P. (1993). Preparation, forms and properties of controlled-release phosphate fertilizers, Fertilizer and lime Research Center, Department of soil Science, Massey University, Palmerstone North, New Zealand, pp 13-24.

19) Gowariker V., Krishnamurthy V. N., Gowariker S., Dhanorkar M. and Paranjape K. (2009). The Fertilizer Encyclopedia, pp 118-119.

20) Estefan S., Abdalla F., Basily A. and Hewaidy I. (1986). Chemical processing of Abu-Tartur phosphate rock for agricultural development in Egypt, Aufbereitungs Technik, 27: 183-187.

21) Weber J., Perry P. and Upchurch R. (1965). The influence of temperature and time on the adsorption of paraquat, diquat, 2,4-D and prometone by clays, charcoal and an anion exchange resin, Soil Sci. Soc. Am Proc., pp 678- 688.

22) Grim R.E. (1968). Clay Mineralogy: $2^{\text {nd }}$ Ed., McGraw-Hill, New York, pp 596. 